\title{
Manifestações dos sintomas da depressão em pacientes com fibromialgia
}

\author{
Manifestations of depression symptoms in patients with fibromyalgia \\ Manifestaciones de sintomas depresíon en pacientes com fibromialgia
}

Francisco Hildebrando Moreira de Oliveira Filho ORCID: https://orcid.org/0000-0002-8362-4374 Instituto de Educação Superior Vale do Parnaíba, Brasil E-mail: bambam.igt@gmail.com

Maria das Graças Resende da Silva Neta

ORCID: https://orcid.org/0000-0002-0945-1751 Instituto de Educação Superior Vale do Parnaíba, Brasil E-mail: gracinharesende@ outlook.com

Lucas Benjamim Pereira Farias

ORCID: https://orcid.org/0000-0002-9133-1475 Instituto de Educação Superior Vale do Parnaíba, Brasil

E-mail: lucasbenjamim35@hotmail.com

Gabrielle Agostinho Rolim Marques

ORCID: https://orcid.org/0000-0002-0036-8126 Instituto de Educação Superior Vale do Parnaíba, Brasil

E-mail: gabrielle.marques@iesvap.edu.br

José Lopes Pereira Júnior

ORCID: https://orcid.org/0000-0001-5621-7469 Instituto de Educação Superior Vale do Parnaíba, Brasil

E-mail: jose.junior@iesvap.edu.br

Ariellen Martins Guerra

ORCID: https://orcid.org/0000-0001-6201-2806 Instituto de Educação Superior Vale do Parnaíba, Brasil

E-mail: ariellenmartins1@ hotmail.com

Guilherme Araújo da Silva

ORCID: https://orcid.org/0000-0001-5579-4459 Instituto de Educação Superior Vale do Parnaíba, Brasil

E-mail: guilherme11araujo@gmail.com

Antônio Victor de Oliveira Machado

ORCID: https://orcid.org/0000-0003-0016-5959 Instituto de Educação Superior Vale do Parnaíba, Brasil

E-mail: victor2711@live.com

Célia Barros de Sousa Marques

ORCID: https://orcid.org/0000-0001-9309-1893 Instituto de Educação Superior Vale do Parnaíba, Brasil

E-mail: celiamarques_@outlook.com

Raquel Araújo Nogueira

ORCID: https://orcid.org/0000-0001-8535-6847 Instituto de Educação Superior Vale do Parnaíba, Brasil

E-mail: raquelaraujo852@gmail.com

Ana Clara Correia Gomes

ORCID: https://orcid.org/0000-0003-2463-0720 Instituto de Educação Superior Vale do Parnaíba, Brasil E-mail: clarinhacorreiaanaclaracorreia@ hotmail.com

Francisco de Nojosa Costa Neto

ORCID: https://orcid.org/0000-0001-8721-5087 Instituto de Educação Superior Vale do Parnaíba, Brasil E-mail: netotoc99@hotmail.com

David Danisio Silva de Freitas

ORCID: https://orcid.org/0000-0003-4003-1971 Instituto de Educação Superior Vale do Parnaíba, Brasil E-mail: fullbringboy@gmail.com

Daniel Barbosa Lima

ORCID: https://orcid.org/0000-0002-0801-4410 Instituto de Educação Superior Vale do Parnaíba, Brasil E-mail: danielbarbosa179@gmail.com

Alyne de Araújo Paiva

ORCID: https://orcid.org/0000-0002-1950-0887 Instituto de Educação Superior Vale do Parnaíba, Brasil E-mail: alynepaivaa@icloud.com 


\begin{abstract}
Resumo
Introdução: A fibromialgia configura-se por manifestações musculoesqueléticas de dor crônica, duradoura, difusa, com a presença de pontos específicos de dor e a ausência de inflamação tecidual. Seu aspecto crônico está intimamente relacionado às alterações de humor, de maneira que estabelece um vínculo bidirecional com a depressão, baseada na ativação de padrões neurais cerebrais que aumentam a sensação de dor. Portanto, a depressão é uma das comorbidades psiquiátricas mais predominante da fibromialgia, com alta taxa de prevalência. Objetivo: Analisar publicações científicas nacionais e internacionais no campo da saúde pública, visando a compreensão das manifestações dos sintomas da depressão nos pacientes com fibromialgia. Metodologia: Trata-se de uma revisão sistemática de literatura onde foram utilizadas as bases de dados: SCIELO, LILACS, MEDLINE e PUBMED. Os descritores utilizados para a coleta de dados foram: Fibromialgia; Depressão; Dor crônica. Os critérios de inclusão foram apenas artigos que abordem a temática em questão, texto completo, encontrados em idioma português, inglês e espanhol nos últimos 5 anos. Resultados: Conforme os resultados obtidos pacientes que possuem fibromialgia apresentam alto índice de depressão. A prevalência de depressão em pacientes com fibromialgia é de 50,5\% a 80\%. Conclusão: Dada a complexidade da avaliação da depressão, mais pesquisas são necessárias para verificar resultados mais confiáveis, como também as características, a influência de fatores não físicos na intensidade e prevalência e o melhor tratamento que atenda às necessidades de pacientes.
\end{abstract}

Palavras-chave: Fibromialgia; Depressão; Dor crônica.

\begin{abstract}
Introduction: Fibromyalgia is characterized by musculoskeletal manifestations of chronic, lasting, diffuse pain, with the presence of specific pain points and the absence of tissue inflammation. Its chronic aspect is closely related to mood changes, in a way that it establishes a bidirectional link with depression, based on the activation of brain neural patterns that increase the sensation of pain. Therefore, depression is one of the most prevalent psychiatric comorbidities of fibromyalgia, with a high prevalence rate. Objective: To analyze national and international scientific publications in the field of public health, aiming to understand the manifestations of depression symptoms in patients with fibromyalgia. Methodology: This is a systematic literature review using the following databases: SCIELO, LILACS, MEDLINE and PUBMED. The descriptors used for data collection were: Fibromyalgia; Depression; Chronic pain. The inclusion criteria were only articles that address the topic in question, full text, found in Portuguese, English and Spanish in the last 5 years. Results: According to the results obtained, patients who have fibromyalgia have a high rate of depression. The prevalence of depression in patients with fibromyalgia ranges from $50.5 \%$ to $80 \%$. Conclusion: Given the complexity of depression assessment, more research is needed to verify more reliable results, as well as characteristics, the influence of non-physical factors on intensity and prevalence, and the best treatment that meets the needs of patients.
\end{abstract}

Keywords: Fibromyalgia; Chronic pain; Depression.

\title{
Resumen
}

Introducción. La fibromialgia se caracteriza por manifestaciones musculoesqueléticas de dolor crónico, duradero, difuso, con presencia de puntos específicos de dolor y ausencia de inflamación tisular. Su aspecto crónico está íntimamente relacionado con los cambios de humor, de forma que establece un vínculo bidireccional con la depresión, basado en la activación de patrones neuronales cerebrales que aumentan la sensación de dolor. Por tanto, la depresión es una de las comorbilidades psiquiátricas más prevalentes de la fibromialgia, con una alta tasa de prevalencia. Objetivo: Analizar publicaciones científicas nacionales e internacionales en el campo de la salud pública, con el objetivo de comprender las manifestaciones de los síntomas depresivos en pacientes con fibromialgia. Metodología: Se trata de una revisión bibliográfica sistemática utilizando las siguientes bases de datos: SCIELO, LILACS, MEDLINE y PUBMED. Los descriptores utilizados para la recolección de datos fueron: Fibromialgia; Depresión; Dolor crónico. Los criterios de inclusión fueron solo artículos que aborden el tema en cuestión, a texto completo, encontrados en portugués, inglés y español en los últimos 5 años. Resultados: De acuerdo con los resultados obtenidos, los pacientes que padecen fibromialgia presentan una alta tasa de depresión. La prevalencia de depresión en pacientes con fibromialgia oscila entre el 50,5\% y el 80\%. Conclusión: Dada la complejidad de la evaluación de la depresión, se necesita más investigación para verificar resultados más confiables, así como las características, la influencia de factores no físicos en la intensidad y prevalencia, y el mejor tratamiento que satisfaga las necesidades de los pacientes.

Palabras clave: Fibromialgia; Dolor crónico; Depresión.

\section{Introdução}

\subsection{Contextualização do problema}

O termo fibromialgia possui origem latina (fibra = tecido fibroso) e grega $($ mio = músculos; algos $=$ algia $=$ dor) .

Dessa forma, a fibromialgia é uma síndrome de dor muscular multifatorial, crônica, de etiologia complexa não elucidada 
totalmente. No entanto, está intrinsecamente relacionado com mecanismos patogênicos, incluindo os fatores genéticos, neuroendócrinos, distúrbios ambientais e alterações psicológicas, como depressão e ansiedade (Barbosa, 2018; Abreu, et al., 2016).

Em 1592, o médico francês Guillaume de Baillou definiu pela primeira vez a fibromialgia de "artrite". O nome da doença passou por várias modificações até chegar ao surgimento da palavra atual. Em 1815, o cirurgião escocês William Balfour, foi o primeiro a identificar os pontos sensíveis da dor. E somente em 1981 foi adotada a nomenclatura "fibromialgia" para definir a doença, além dos critérios diagnósticos de dor difusa acompanhada de rigidez em três ou mais áreas anatômicas, por mais de três meses (Barbosa, 2018; Luiz, 2017).

Sendo assim, a fibromialgia é caracterizada por manifestações musculoesqueléticas de dor crônica, duradoura, difusa com a presença de pontos específicos de dor e a ausência de inflamação tecidual. Não obstante, é uma patologia complexa e possui prevalência significativa na população geral. (Barbosa, 2018; Luiz, 2017; Avila, Lazslo A. et al 2014).

A fibromialgia abrange de $3 \%$ a $10 \%$ da população mundial total e em torno de $2,5 \%$ da população brasileira, considerada a segunda doença reumática mais comum, depois da osteoartrite. O sexo feminino representa cerca de 70 a $90 \%$ dos casos, principalmente mulheres de 35 a 55 anos de idade (Muhammad, 2019; Gondim, 2018; Conte, et al., 2018; Ziani, et al., 2017; Luiz, 2017).

Em 1995, na cidade de Wichita, nos Estados Unidos, foram coletados os primeiros dados epidemiológicos ligados à fibromialgia. Foi evidenciado que $2 \%$ da população, dentre eles 3,4\% sexo feminino e 0,5\% sexo masculino, eram fibromiálgicos, com maior prevalência entre 60 e 79 anos. Em 2008, na França constatou-se uma prevalência de 1,4\% de fibromiálgicos (Azevedo, 2019). Na Europa, estudos evidenciaram que a incidência da fibromialgia é de 1,3\%, atingindo 1 a $2 \%$ da população francesa, entre 25 e 30 anos, sendo $70 \%$ mulheres (Ferreira, 2015).

A depressão apresenta uma das comorbidades psiquiátricas mais comuns, com taxa de prevalência referente a 18 a 36\% (Işik-Ulusoy, 2019). Nesse contexto, os pensamentos debilitantes além de afetar de forma negativa os aspectos da vida cotidiana, ela interfere veementemente nas atividades pessoais, familiares, laborais e pessoais, ocasionando um estado de catastrofização reduzindo atividades diárias e promovendo o isolamento social. (Muhammad, 2019; Meireles, 2016; Ferreira, 2015; De Oliveira, Anita et al., 2014).

A partir da ativação dos padrões neurais cerebrais que intensificam a sensação de dor, o aspecto crônico da fibromialgia está concomitantemente relacionado às alterações do humor, além de possuir um vínculo bidirecional com a depressão. (Muhammad, 2019; Luiz, 2017; Coelho, 2016).

Os hormônios noradrenalina, serotonina e dopamina, estão diretamente relacionados pela boa qualidade de vida do indivíduo, a deficiência na produção desses, está ligado a depressão e ao mecanismo doloroso peculiar da fibromialgia (Meireles, 2016).

Dentre os vários polimorfismos explorados em paciente com fibromialgia, destaca-se o gene transportador de serotonina SLC6A4, localizado no cromossomo 17q11. 1-q12, um polimorfismo funcional na região reguladora 5' proximal, é definido como 5-HTTLPR, caracterizado por possuir de um alelo longo "L" e um alelo curto "S". A transcrição do gene transportador de serotonina (5-HTT) é aproximadamente 3 vezes mais eficiciente em homozigotos L/L na região promotora do que nos portadores da variante $S$.

A investigação da frequência dos alelos constatou que o genótipo curto se apresenta com maior frequência em pacientes fibromiálgicos, além de estar relacionado ao aparecimento deste genótipo e de distúrbios psicológicos e transtornos depressivos (Almeida, et al., 2016).

Esta peculiaridade do 5-HTT ocasiona no aumento da expressão da proteína transportadora e da captação celular de serotonina no neurônio serotoninérgico pré-sináptico, diminuindo os níveis de 5-HTT no soro, no líquor e nos níveis dos seus 
precursores em indivíduos fibromiálgicos. Desse modo, a redução da disponibilidade de serotonina na fenda sináptica nas áreas corticais e pré-corticais, aumentam a susceptibilidade e percepção da dor (Almeida, et al., 2016; Abreu, et al., 2016). Além disso, a 5-HTT atua também no humor, comportamento, emoções, memória, controle do sono/despertar e vias sensitivas (Alves, et al., 2014).

Pela relevância do tema, os autores elaboraram este artigo de revisão a partir de investigação exploratória, qualitativa e bibliográfica com objetivo de estudar os principais aspectos clínicos, dentre eles as características da doença e a correlação da fibromialgia com a depressão, dando ênfase ao embasamento teórico-conceitual.

Nesse sentido a pesquisa tem como objetivo geral analisar as publicações científicas nacionais e internacionais no campo da saúde pública, visando o entendimento das manifestações dos sintomas da depressão nos pacientes com fibromialgia.

\section{Metodologia}

\subsection{Tipos de estudos}

Trata-se de uma pesquisa de revisão integrativa com abordagem qualitativa. Sendo assim, conforme Soares et al. (2011) a pesquisa bibliográfica consiste no exame da literatura científica e levantamento, além de análise do que já se produziu sobre determinado tema. Envolvem também as atividades básicas de identificação, fichamento, compilação, interpretação e análise.

Já a pesquisa descritiva ocorre quando o pesquisador tem por intuito descrever as características de certa população ou fenômeno e estabelecer relações através de variáveis, sem sua manipulação (Gil, 2017).

A pesquisa bibliográfica é a fase fundamental para o trabalho científico, pode ser realizada em apenas uma fase de uma pesquisa experimental ou descritiva, ou pode ser uma pesquisa em si. A pesquisa bibliográfica consiste no fundamento necessário e básico para a realização de estudos monográficos, é considerada parte fundamental para o estudo exploratório, devendo acompanhar, registros, notas de aulas, anotações, além de apontamentos que estejam relacionados com o tema de interesse. (Soares, et, al., 2018)

\subsection{Questão norteadora}

A construção da pergunta norteadora é uma parte importante para a criação do trabalho científico, uma vez que define os meios que serão adotados para a coleta de dados, identificação e informações. Diante disso, surge então uma questão que motiva a elaboração desse projeto, sendo a pergunta norteadora: Quais as manifestações clínicas da depressão nos pacientes fibromialgicos na literatura científica?

\subsection{Período da pesquisa}

A pesquisa dos artigos foi realizada por meio da busca no Portal Regional da BVS, (biblioteca virtual em saúde). A BVS Brasil tem o propósito de unir as redes temáticas brasileiras da BVS e integrar suas redes de fontes de informação em saúde, fortalecendo-as e dando visibilidade às mesmas por meio do Portal da BVS Brasil. As fontes de informação são oriundas das BVS Temáticas Nacionais, obedecendo a seus controles de qualidade e metodologias (BVS, 2017).

Os critérios de inclusão foram apenas artigos que abordem a temática em questão, texto completo, encontrados em idioma português, inglês e espanhol e nos últimos 5 anos, assim como pesquisas de campo e estudo de caso.

Os critérios de exclusão foram: artigos duplicados, trabalhos científicos que foram publicados em outras línguas e artigos que não se encontram no enfoque do tema principal. 
Figura 1. Fluxograma de amostragem da revisão integrativa.

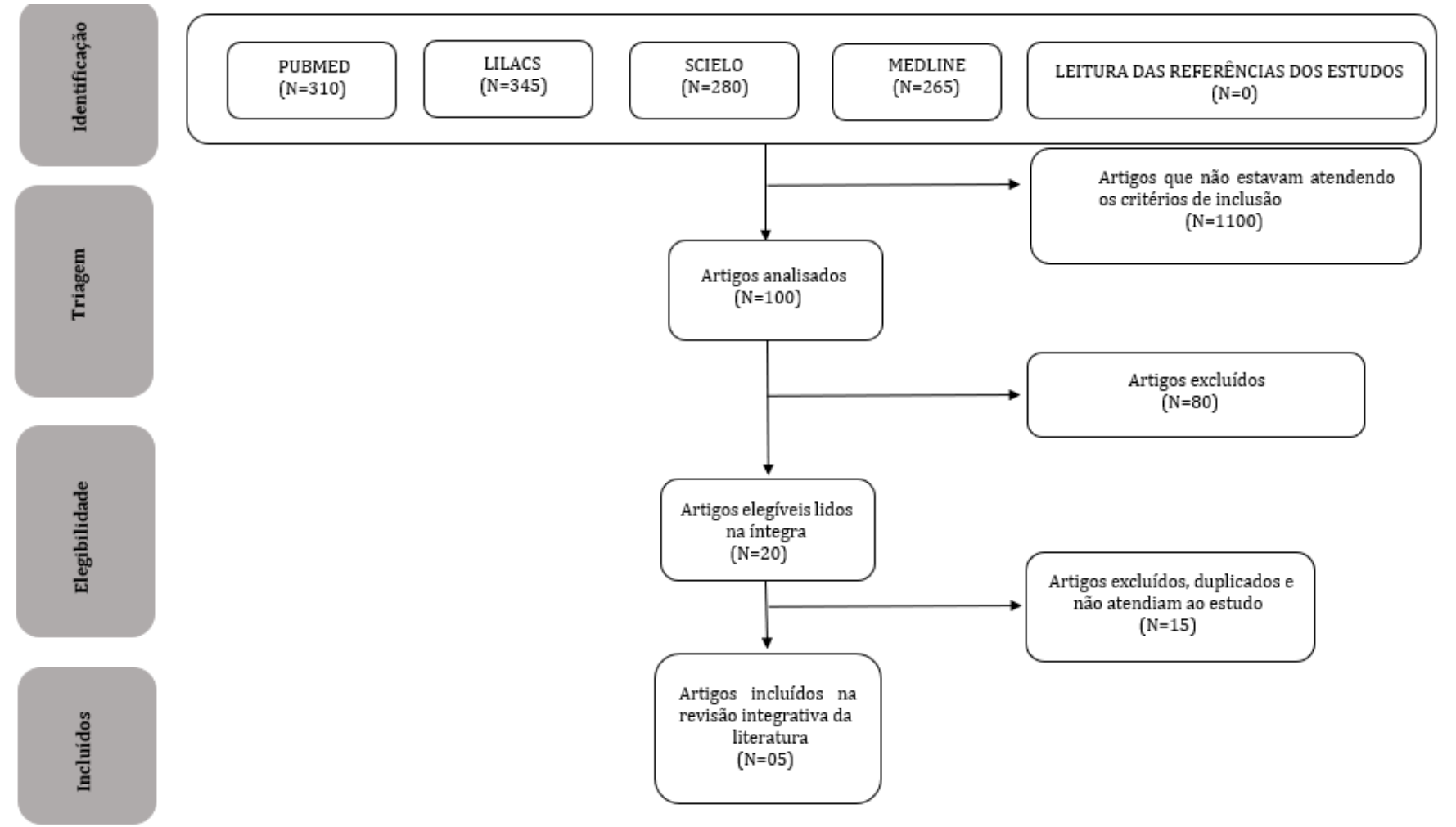

Fonte: Autores (2021).

\subsection{Aspectos éticos}

Todas as produções utilizadas neste estudo foram rigorosamente referenciadas de acordo com as normas da Associação Brasileira de Normas Técnicas (ABNT, 2013-2014). Esta pesquisa foi realizada de acordo com a Lei dos Direitos Autorais, que consiste na Lei ${ }^{\circ} 9.610$ de fevereiro de 1998, portanto essa pesquisa foi devidamente conduzida no sentido de não cometer plágio, sempre realizando devidamente a citação de fontes e autoria e dispensando tratamentos adequados aos dados obtidos (Brasil, 1998).

\section{Resultados e Discussão}

Apresenta-se a seguir alguns achados de acordo com o processo de inclusão e exclusão. Após a filtração ficaram 5 artigos no total. 
Tabela 1. Compilação dos artigos analisados.

\begin{tabular}{|c|c|c|c|c|c|}
\hline $\begin{array}{l}\text { Periódico/ } \\
\text { Ano de } \\
\text { publicação }\end{array}$ & Título & Autores & $\begin{array}{l}\text { Tipo de } \\
\text { pesquisa }\end{array}$ & Ideia central & Resultados encontrados \\
\hline $\begin{array}{l}\text { SCIELO } \\
2016\end{array}$ & $\begin{array}{l}\text { A Fibromialgia e a } \\
\text { Manifestação de } \\
\text { Sofrimento Psíquico }\end{array}$ & $\begin{array}{l}\text { SILVA; T.A.D. } \\
\text { RUMIM; C.R. }\end{array}$ & $\begin{array}{c}\text { Relato de } \\
\text { experiencia }\end{array}$ & $\begin{array}{l}\text { Oferecer acolhimento às } \\
\text { manifestações de sofrimento } \\
\text { psíquico apresentadas pelas } \\
\text { trabalhadoras }\end{array}$ & $\begin{array}{l}\text { Ao oferecer acolhimento e ressignificação aos } \\
\text { afetos, a atenção psicoterapêutica contribuiu para } \\
\text { a manutenção do quadro geral de saúde, } \\
\text { amenizando vivências dissociativas e levando a } \\
\text { reflexões sobre formas de atendimento } \\
\text { interdisciplinar. }\end{array}$ \\
\hline $\begin{array}{c}\text { SCIELO } \\
2017\end{array}$ & $\begin{array}{l}\text { Quando a perda de } \\
\text { sentidos no mundo } \\
\text { do trabalho implica } \\
\text { dor e sofrimento: } \\
\text { um estudo de caso } \\
\text { sobre fibromialgia }\end{array}$ & $\begin{array}{c}\text { MATTOS; R.S. } \\
\text { LUZ; M.T. }\end{array}$ & $\begin{array}{l}\text { Estudo de } \\
\text { caso. }\end{array}$ & $\begin{array}{l}\text { A perda dos sentidos positivos em } \\
\text { relação ao trabalho e o o } \\
\text { desencantamento com a atividade } \\
\text { laboral implicam dor e sofrimento }\end{array}$ & $\begin{array}{l}\text { A fibromialgia vem juntar-se aos casos de LER e } \\
\text { DORT como efeito da reestruturação da relação } \\
\text { capital-trabalho nas últimas décadas. }\end{array}$ \\
\hline $\begin{array}{c}\text { SCIELO } \\
2020\end{array}$ & $\begin{array}{l}\text { Avaliação da } \\
\text { qualidade de vida e } \\
\text { comprometimento } \\
\text { funcional } \quad \text { em } \\
\text { pacientes com } \\
\text { fibromialgia }\end{array}$ & CRUZ; B.D. & $\begin{array}{l}\text { Estudo de } \\
\text { caso. }\end{array}$ & $\begin{array}{l}\text { O estudo vai analisar, portanto, o } \\
\text { impacto da Fibromialgia na } \\
\text { qualidade de vida desse grupo e } \\
\text { avaliar o comprometimento } \\
\text { funcional trazido pelo curso da } \\
\text { doença, bem como as } \\
\text { comorbidades } \\
\text { frequentemente associadas ao } \\
\text { impacto na qualidade de vida e } \\
\text { comprometimento funcional nessa } \\
\text { população. }\end{array}$ & $\begin{array}{l}\text { É somente com atendimento do paciente como } \\
\text { um todo e com a abordagem multidisciplinar que } \\
\text { se possibilitará evitar o problema do diagnóstico } \\
\text { tardio. }\end{array}$ \\
\hline $\begin{array}{l}\text { SCIELO } \\
2016\end{array}$ & $\begin{array}{l}\text { Achados } \\
\text { vestibulares em } \\
\text { pacientes portadores } \\
\text { de fibromialgia. }\end{array}$ & $\begin{array}{l}\text { ZEIGELBOIM; } \\
\text { B.S. MOREIRA; } \\
\text { D.N. }\end{array}$ & $\begin{array}{l}\text { Estudo } \\
\text { retrospectivo } \\
\text { de corte } \\
\text { transversal. }\end{array}$ & $\begin{array}{l}\text { importância do exame labiríntico } \\
\text { o que ressalta que esse tipo de } \\
\text { população deveria ser melhor } \\
\text { estudada, uma vez que diversas } \\
\text { doenças reumatológicas pelas suas } \\
\text { manifestações e áreas de } \\
\text { comprometimento podem gerar } \\
\text { alterações } \\
\text { importantes }\end{array}$ & $\begin{array}{l}\text { A fibromialgia (FM) é uma síndrome } \\
\text { musculoesquelética não inflamatória, de caráter } \\
\text { crônico, de etiologia desconhecida, caracterizada } \\
\text { por dor difusa, aumento da sensibilidade na } \\
\text { palpação e por sintomas como fadiga, insônia, } \\
\text { ansiedade, depressão, intolerância ao frio e } \\
\text { queixas otológicas. }\end{array}$ \\
\hline $\begin{array}{c}\text { SCIELO } \\
2018\end{array}$ & $\begin{array}{ll}\text { Depressão } & \text { em } \\
\text { pacientes } & \\
\text { fibromiálgicos } & \mathrm{em} \\
\text { tratamento } & \\
\text { fisioterapêutico } & \end{array}$ & $\begin{array}{c}\text { MELO; R.S. } \\
\text { PEREIRA; T.R. }\end{array}$ & $\begin{array}{l}\text { Estudo de } \\
\text { caso. }\end{array}$ & $\begin{array}{l}\text { A prevalência de } \\
\text { encontrada foi alta, observana } \\
\text { alto índice nos pacientes } \\
\text { portadores de fibromialgia, } \\
\text { entretanto o tratamento } \\
\text { fisioterapêutico pouco beneficia o } \\
\text { sintoma de depressão em } \\
\text { pacientes fibromiálgicos. }\end{array}$ & $\begin{array}{l}\text { Após a aplicação do questionário e análise dos } \\
\text { dados obtidos observou-se que } 78 \% \\
\text { apresentavam algum tipo de depressão mesmo } \\
\text { estando em tratamento de fisioterapia. }\end{array}$ \\
\hline
\end{tabular}

Fonte: Autores (2021).

\section{A depressão e suas caraterísticas}

Segundo Silva e Rumim (2016) a depressão inclui não apenas alterações emocionais, como tensão, insatisfação, incapacidade de se sentir feliz e inatividade, mas também vários aspectos, incluindo alterações psicomotoras, cognitivas e nutricionais, incluindo sono e apetite. Os sintomas básicos da depressão estão relacionados a queixas físicas, como dores no corpo, desconforto incerto, formigamento, cabeça e corpo vazios, tremores, aperto no peito, ansiedade, etc. Esta doença pode ser facilmente confundida com outras doenças.

Para Mattos e Luz (2017) a depressão é uma doença multifatorial que envolve a relação entre o meio ambiente, predisposições genéticas e eventos que ocorrem ao longo do desenvolvimento. Portanto, a depressão é causada pela soma de vários fatores internos e externos que desencadeiam alterações neuropsicológicas no sistema nervoso central, incluindo conflito interpessoal (separação, conflito conjugal, fim do relacionamento, falta de diálogo), fatores pessoais (para cigarros, álcool e drogas).

Na visão de Cruz (2020) o impacto social da depressão inclui deficiência pessoal e carga familiar relacionada à doença. Além disso, a depressão grave e os sintomas depressivos são problemas comuns e importantes de saúde pública, 
porque os custos com saúde, a perda de tempo de trabalho e a redução da qualidade de vida estão claramente relacionados à depressão. Embora seja uma doença crônica, a depressão ainda é uma doença tratável. Nos últimos 25 anos, houve um grande desenvolvimento nos métodos de tratamento. Além disso, sintomas depressivos ainda menos graves são importantes porque sua presença está relacionada ao desenvolvimento de outras doenças mentais mais graves.

Zeigelboim e Moreira (2016) retratam que a depressão pode piorar as funções sociais e emocionais. Pessoas com depressão são propensas ao isolamento, ao fracasso e à depressão, tornando seus relacionamentos com outras pessoas difíceis e emocionalmente deprimidos. Fatores psicossociais desempenham um papel importante na etiologia e evolução da fibromialgia. Isso inclui fatores comportamentais, como comportamentos de risco e estratégias de enfrentamento mal ajustadas; fatores cognitivos, como vitimização e perda de autocontrole e fatores sociais, como interferência no papel do indivíduo na sociedade.

Nota-se nos estudo que a compreensão da fibromialgia com o tempo, ocasiona uma dor invisível para aqueles que não sentem tornando-se irritante e podendo levar a estímulos discriminatórios e a comportamentos perigosos. Isso fará com que os pacientes precisem da atenção de familiares e amigos, portanto, pode se tornar um gerador de benefícios secundários.

Tudo isso pode ser compreendido pelos problemas causados pela dor crônica na fibromialgia. Como as estratégias de enfrentamento do paciente são prejudicadas, ele tende a evitar amizades, responsabilidades financeiras e até mesmo atividades físicas. Essa série de eventos acaba levando ao agravamento dos sintomas depressivos, formando um círculo vicioso. Além disso, a depressão complica o curso de qualquer doença através de vários mecanismos possíveis: aumento da percepção da dor, diminuição da adesão ao tratamento, diminuição do apoio social e desregulação dos fluidos corporais e do sistema imunológico.

\section{A fibromialgia e suas manifestações}

Para Melo e Pereira (2018) Notou-se durante as leituras dos achados que a fibromialgia é um tipo de dor crônica caracterizada por interferência fisiológica e comportamental. Ela mostra alterações na conformação genética, neuroendócrina e sócio-psicológica, que acaba levando à depressão causada ou exacerbada pelo processo de dor, relacionados a esses fatores, alguns neurotransmissores, principalmente a disfunção da serotonina, podem causar problemas e aumentar a possibilidade de depressão, afetando diretamente a fibromialgia.

Segundo Silva e Rumim (2016) A fibromialgia pode ser caracterizada sendo uma síndrome de dor crônica. O principal sintoma é a dor muscular difusa. Não é causado por nenhum dano articular ou processo inflamatório, dura mais de três meses sendo acompanhado por outros sintomas como fadiga, falta de sono, rigidez matinal, prisão de ventre ou diarreia, ranger de dentes, dor de cabeça, ansiedade e depressão.

Para Mattos e Luz (2017) como a expressividade da dor crônica está diretamente relacionada às alterações de humor dos pacientes com fibromialgia, a ansiedade e a depressão constituem uma conexão de mão dupla, de modo que as características e especificidade da dor crônica levam ao aumento desses fatores, o que leva à amplificação da dor. Portanto, a fibromialgia e vários aspectos da ansiedade e da depressão podem ser desencadeadores um do outro.

Na visão de Cruz (2020) a etiologia e fisiopatologia da fibromialgia ainda não são claras. Essas hipóteses sugerem que a disfunção fisiopatológica da FM pode ser geneticamente predeterminada e desencadeada por fatores ambientais, como infecção viral, estresse psicológico ou trauma físico e fatores hormonais. Portanto, fatores genéticos e ambientais influenciam no aparecimento da fibromialgia.

Nota-se nos estudo que as manifestações da fibromialgia são dores difusas, crônicas e generalizadas, que aparecem em ambos os lados do corpo, acima e abaixo do tronco e nos ossos axiais e duram mais de três meses. Por outro lado, a dor no estado inicial é geralmente localizada, sendo mais comum no pescoço e nos ombros. Portanto, com o tempo, muitos pacientes com FM sentirão dor crônica em diferentes partes do corpo, como cefaleia, dismenorreia, doença da articulação 
temporomandibular e dor lombar crônica. Ao descrever as características da dor, ela é descrita principalmente como dores musculares e articulares.

\section{Manifestações dos sintomas da depressão em pacientes com fibromialgia}

A emoção pode ser entendida como uma resposta automática, inconsciente ou consciente, forte e rápida. É dotada de estímulos e impulsos neuronais para guiar o organismo a produzir ações. Como um catalisador entre o comportamento e o ambiente, pode ser afetada. Segundo Silva e Rumim (2016) Pacientes com fibromialgia têm dificuldades especiais em reconhecer suas emoções. Reações patológicas e fisiológicas, como a fibromialgia, onde as principais queixas de dor, fadiga e diminuição da função física podem levar a ansiedade, estresse, depressão e distúrbios de humor, que podem afetar a qualidade do sono e os aspectos cognitivos da fibromialgia.

Para Mattos e Luz (2017) A correlação entre dor e limitações de capacidade também apoia a compreensão de como essa síndrome funciona e seu poder debilitante.

Na visão de Cruz (2020) Na outra ponta do espectro, em relação à autopercepção de saúde e vitalidade, um dado interessante refere-se aos comportamentos dolorosos desses pacientes, o que faz parte da baixa vitalidade e das percepções negativas de saúde nos mesmos. As pessoas podem considerar a dor um sintoma, mas também estar em um ambiente psicológico que inclui aqueles afetados por síndromes de dor crônica, que evoluem da própria dor para posturas evitativas e pessimistas, o que é muito importante em vários cenários de pesquisa.

Para Melo e Pereira (2018) a perseguição associada à farsa da doença pode se tornar instável com o resgate de funções desempenhadas até por pessoas doentes. No entanto, a partir da possibilidade de participação social e da expressão de suas respectivas limitações, deve-se considerar a conscientização da rede de relacionamentos. Desde então, os membros da equipe estão definitivamente dispostos a contribuir com projetos sociais em benefício de outras pessoas. Desejo de pertencer a um grupo social e usufruir dos seus elementos identitários associados ao processo de identificação, em que possam usufruir da experiência única de acolhimento.

Segundo Silva e Rumim (2016) o auxílio aos trabalhadores com diagnóstico de fibromialgia proporciona a percepção dos sintomas físicos como forma de expressar a dor e o comprometimento da motivação mental. A ação explicativa sobre a experiência geral de ansiedade reposiciona as emoções e estabelece um espaço contido para ouvir e acolher a dor. A comunicação emocional aproxima os membros de diferentes referências sobre o cotidiano que a doença atravessa e se configura como possibilidade de reconhecimento e diferenciação.

Nota-se nos estudo que talvez a maior dificuldade diagnóstica seja distinguir a fibromialgia do reumatismo psicogênico. Em alguns casos, a condição clínica do paciente é puramente uma manifestação de transtornos mentais, especialmente depressão. É bem conhecido que os pacientes com fibromialgia desenvolvem depressão com mais frequência do que os pacientes com artrite reumatoide. Cerca de metade dos pacientes com fibromialgia já experimentou depressão em sua história (Melo; Pereira, 2018).

Muitos sintomas da depressão, como cansaço, sensação de perda de energia, depressão ou distúrbios do sono, são iguais aos da fibromialgia. No entanto, deve ser lembrado que uma grande proporção de pacientes com fibromialgia não apresenta depressão ou qualquer componente de doença mental (CRUZ,2020)

\section{Conclusão}

A fibromialgia é entendida como um tipo de dor crônica, que se caracteriza por distúrbios físicos e comportamentais, que exibem alterações na conformação genética, neuroendócrina e sócio-psicológica e, por fim, levam à depressão causada ou 
Research, Society and Development, v. 10, n. 15, e63101522587, 2021

(CC BY 4.0) | ISSN 2525-3409 | DOI: http://dx.doi.org/10.33448/rsd-v10i15.22587

exacerbada pelo processo doloroso. Desse modo, a fibromialgia pode causar depressão, assim como a depressão pode afetar a fibromialgia

Portanto, por essas duas patologias possuírem etiologia multifatorial e coexistência significativa, juntas podem ter um potencial impacto negativo na vida dos pacientes e interferir nas atividades diárias, na qualidade do sono, e no humor. Reforçase o valor do cuidado individualizado e a necessidade de novas pesquisas neste campo para facilitar o diagnóstico e melhorar a qualidade de vida dos pacientes.

As discussões apresentadas pela pesquisa e as evidências trazidas pela literatura também têm reforçado a necessidade de se compreender o mecanismo psicossocial biológico da fibromialgia, pois só assim pode haver qualificação suficiente para lidar corretamente, cruzar e aceitar essa situação.

\section{Referências}

Abreu, A. M. L. D. R. (2016). Limiares de dor, níveis séricos e variantes genéticas de serotonina em fibromialgia: uma associação de base familar.

Almeida, T. A. G., Tischer, T. R., de Paula, H. D. S. C., Silva, A. M. T. C., \& Saddi, V. A. (2016). Análise do polimorfismo na região promotora do transportador de serotonina (5-htt) em pacientes com fibromialgia e controles saudáveis. Revista EVS-Revista de Ciências Ambientais e Saúde, 43, 2-8.

Avila, L. A., Araujo, G. M. D., Guimarães, E. F., Gonçalves, L., Paschoalin, P. N., \& Aleixo, F. B. (2014). Caracterização dos padrões de dor, sono e alexitimia em pacientes com fibromialgia atendidos em um centro terciário brasileiro. Revista brasileira de Reumatologia, 54, 409-413.

Azevedo, P. M. (2019). A ciência da dor: Sobre fibromialgia e outras síndromes dolorosas. Editora UNESP.

Barbosa-Torres, C., López-López, L., \& Cubo-Delgado, S. (2018). El síndrome de fibromialgia y su tratamiento. Ciencias Y Humanidades De La Salud, 5(3), $103-115$.

Canale, A., \& Furlan, M. M. D. P. (2007). Depressão. Arquivos do MUDI, 11(1), 23-31.

Coelho, C. (2016). Ansiedade e Depressão na Fibromialgia. Psicologia. PT, 1-16.

Conte, M. S., Dumbra, G. A. C., Roma, D. V. P., da Silva Fucuta, P., \& Miyaza, M. C. D. O. S. (2018). Fibromialgia: atividade física, depressão e qualidade de vida. Medicina (Ribeirão Preto), 51(4), 281-290.

DA ANVISA, B. E., \& Brasília, D. F. ANVISA-Agência Nacional de Vigilância Sanitária. Acesso em, 10.

de Oliveira e Souza, A., Matias, R. N., da Silva, M. S., Donadon, R. A., \& da Silva, D. O. F. (2014). Fibromialgia e depressão: uma relação indefinida. Revista de Medicina e Saúde de Brasília, 3(2).

DUAILIBI, K., SILVA, A., \& JUBARA, C. (2013). Como diagnosticar e tratar depressão. Revista Brasileira de Medicina, 71(12), 23 -31.

Ferreira, A. J. O. (2015). Fibromialgia: conceito e abordagem clínica (Doctoral dissertation).

Frantz, P. J. (2018). Impacto da fibromialgia e fatores associados em uma população do sul do Brasil. Programa de Pós-Graduação em Ciência da Saúde.

Furlanetto, L. M., \& Brasil, M. A. (2006). Diagnosticando e tratando depressão no paciente com doença clínica. Jornal Brasileiro de Psiquiatria, 55, 8-19.

GIL, A. (2017). Capítulo 5: Como delinear uma pesquisa bibliográfica. Como elaborar projetos de pesquisa. Atlas,

Gondim, S. S., \& Almeida, M. A. P. T. (2018). Os efeitos da massagem terapêutica manual em pacientes com a síndrome da fibromialgia. ID on line REVISTA DE PSICOLOGIA, 12(39), 336-354.

HELMAN, C. G. (2009). Cultura, Saúde e Doença. Tradução Ane Rose Bolner.

Homann, D., Stefanello, J. M. F., Góes, S. M., Breda, C. A., Paiva, E. D. S., \& Leite, N. (2012). Percepção de estresse e sintomas depressivos: funcionalidade e impacto na qualidade de vida em mulheres com fibromialgia. Revista Brasileira de Reumatologia, 52, 324-330.

Işı-Ulusoy, S. (2019). Evaluation of affective temperament and anxiety-depression levels in fibromyalgia patients: a pilot study. Brazilian Journal of Psychiatry, 41, 428-432.

Lorena, S. B. D., Pimentel, E. A. D. S., Fernandes, V. M., Pedrosa, M. B., Ranzolin, A., \& Duarte, A. L. B. P. (2016). Avaliação de dor e qualidade de vida de pacientes com fibromialgia. Revista dor, 17, 8-11.

Luiz, F. R., \& Raupp, L. M. (2017). Grupo de apoio psicológico a portadores da síndrome fibromialgia: relato de experiência. Saúde e Desenvolvimento Humano, 5(3), 53-63.

Meireles, C. (2016). Ansiedade e depressão codificadas pela CIF em pacientes com fibromialgia.

Melo, L. T. D. (2020). Efeitos do dry needling em pacientes com fibromialgia: uma revisão de literatura. Fisioterapia-Tubarão. 
Research, Society and Development, v. 10, n. 15, e63101522587, 2021

(CC BY 4.0) | ISSN 2525-3409 | DOI: http://dx.doi.org/10.33448/rsd-v10i15.22587

Moraes, R. S. A. M. D., Silva, D. A. S., Oliveira, W. F. D., \& Peres, M. A. (2017). Social inequalities in the prevalence of common mental disorders in adults: a population-based study in Southern Brazil. Revista Brasileira de Epidemiologia, 20, 43-56.

Muhammad, J. S., \& Ishaq, M. (2019). Increased risk of anxiety and depression associated with chronic pain and fibromyalgia in Pakistani population. Biomed Res, 4, 1-5.

Perea, D. C. B. N. M. (2003). Fibromialgia: epidemiologia, diagnóstico, fisiopatologia e tratamento fisioterápico. Fisioterapia Brasil, 4(4), $282-288$.

Pereira, A. L. S. (2013). Exercício físico no controle e prevenção da ansiedade e depressão.

Rodrigues, F. P. (2019). Revisão integrativa sobre depressão, atividade física e exercício físico. Revista Científica UMC, 4(3).

Soares, S. V., Picolli, I. R. A., \& Casagrande, J. L. (2018). Pesquisa bibliográfica, pesquisa bibliométrica, artigo de revisão e ensaio teórico em administração e contabilidade. Administração: ensino e pesquisa, 19(2), 308-339.

Teodoro, W. L. G. (2018). Depressão: corpo, mente e alma. Wagner Luiz Garcia Teodoro.

Ziani, M. M., Bueno, E. A., Kipper, L. R., Vendrusculo, F. M., Winck, A. D., \& Heinzmann-Filho, J. P. (2017). Efeitos da terapia manual sobre a dor em mulheres com fibromialgia: uma revisão de literatura. Ciência \& Saúde, 10(1), 48-55. 